\title{
MASTER
}

\section{Internal Disruptions in Tokamaks}

\author{
Bruce V. Waddell \\ Gary L. Jahns \\ James D. Callen \\ H. Richard Hicks
}

\section{OAK RIDGE NATIONAL LABORATORY}




\section{DISCLAIMER}

This report was prepared as an account of work sponsored by an agency of the United States Government. Neither the United States Government nor any agency Thereof, nor any of their employees, makes any warranty, express or implied, or assumes any legal liability or responsibility for the accuracy, completeness, or usefulness of any information, apparatus, product, or process disclosed, or represents that its use would not infringe privately owned rights. Reference herein to any specific commercial product, process, or service by trade name, trademark, manufacturer, or otherwise does not necessarily constitute or imply its endorsement, recommendation, or favoring by the United States Government or any agency thereof. The views and opinions of authors expressed herein do not necessarily state or reflect those of the United States Government or any agency thereof. 


\section{DISCLAIMER}

Portions of this document may be illegible in electronic image products. Images are produced from the best available original document. 


\section{Printed in the United States of America. Available from National Technical Information Service \\ U.S. Department of Commerce \\ 5285 Port Royal Road, Springfield, Virginia 22161 \\ Price: Printed Copy $\$ 4.00$; Microfiche $\$ 3.00$}

This report was prepared as an account of work sponsored by the United States Government. Neither the United States nor the Energy Research and Development Administration/United States Nuclear Regulatory Commission, nor any of their employees, nor any of their contractors, subcontractors, or their employees, makes any warranty, express or implied, or assumes any legal liability or responsibility for the accuracy, completeness or usefulness of any information, apparatus, product or process disclosed, or represents that its use would not infringe privately owned rights. 
Contract No. W-7405-eng-26

Fusion Energy Division

INTERNAL DISRUPTIONS IN TOKAMAKS

Bruce V. Wadde11

Gary L. Jahns

James D. Callen

H. Richard Hicks

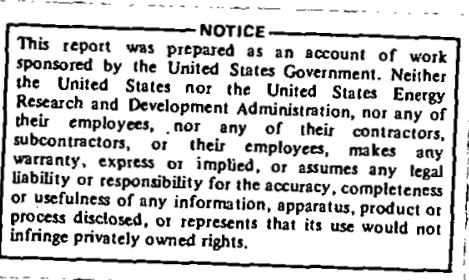

Date Published - May 1977

Prepared by the

OAK RIDGE NATIONAL LABORATORY

Oak Ridge, Tennessee $\mathbf{3 7 8 3 0}$

operated by 
THIS PAGE

WAS INTENTIONALLY

LEFT BLANK 


\begin{abstract}
We hypothesize that sawtooth oscillations are the result of a cyclic process in which the plasma core is resistively heated until the safety factor drops below unity, causing the $m=1$ tearing mode to become unstable, to grow with an accelerating growth rate, and ultimately to flatten the electron temperature and safety factor profiles. A model based on this hypothesis compares favorably with experimental data from ORMAK in explaining 1) the rate at which a sawtooth rises, 2) the radial dependence of the precursor and main sawtooth oscillation amplitudes, 3) the accelerating growth of the $m=1$ precursor oscillations, and 4) the repetition time of the sawteeth.
\end{abstract}


Since their discovery in 1974, "sawtooth oscillations," which are sometimes referred to as "minor" or "internal disruptions," have remained one of the intriguing mysteries of tokamak discharges. Von Goeler et a1. 1 observed that as a function of time, the soft $x$-ray emission from the plasma core exhibited a sawtooth structure (see Fig. 1). In the ORMAK device, the sawteeth are characterized by a period or repetition time of approximately $1 \mathrm{msec}$ and a disruption time of about 50-100 $\mu \mathrm{sec}$. The growth rate of the $\mathrm{m}=1$ oscillations preceding the disruptions is $1-5 \mathrm{msec}^{-1}$; here $\mathrm{m}$ denotes the poloidal mode number. The importance of sawtooth oscillations regarding overall plasma confinement has not presently been clarified. We present a series of arguments and comparisons with experiment which indicate that a reasonably consistent model of the sawtooth oscillations can be developed from the concept that the slow rise of a given sawtooth is due to ohmic heating while the disruptive part is due to the nonlinear growth of the $m=1$ tearing mode, modified by diamagnetic drifts.

An explanation of the disruptive part of the sawtooth has provided the motivation for several theoretical efforts. Von Goeler et al. observed that the growth rate of the $m=1$ ideal MHD internal kink mode is approximately seven times too large to explain the observed growth rate of the $m=1$ oscillations. ${ }^{1}$ Furthermore, Rosenbluth showed that in the low $B$ limit, the ideal internal kink instability should saturate at an amplitude much lower than the amplitude inferred from experiment. ${ }^{2}$ Later, however, Kadomtsev argued heuristically that resistivity should prevent the saturation of the internal kink at low amplitudes and thus allow the magnetic field to evolve in such a way that the current density, safety factor, and 


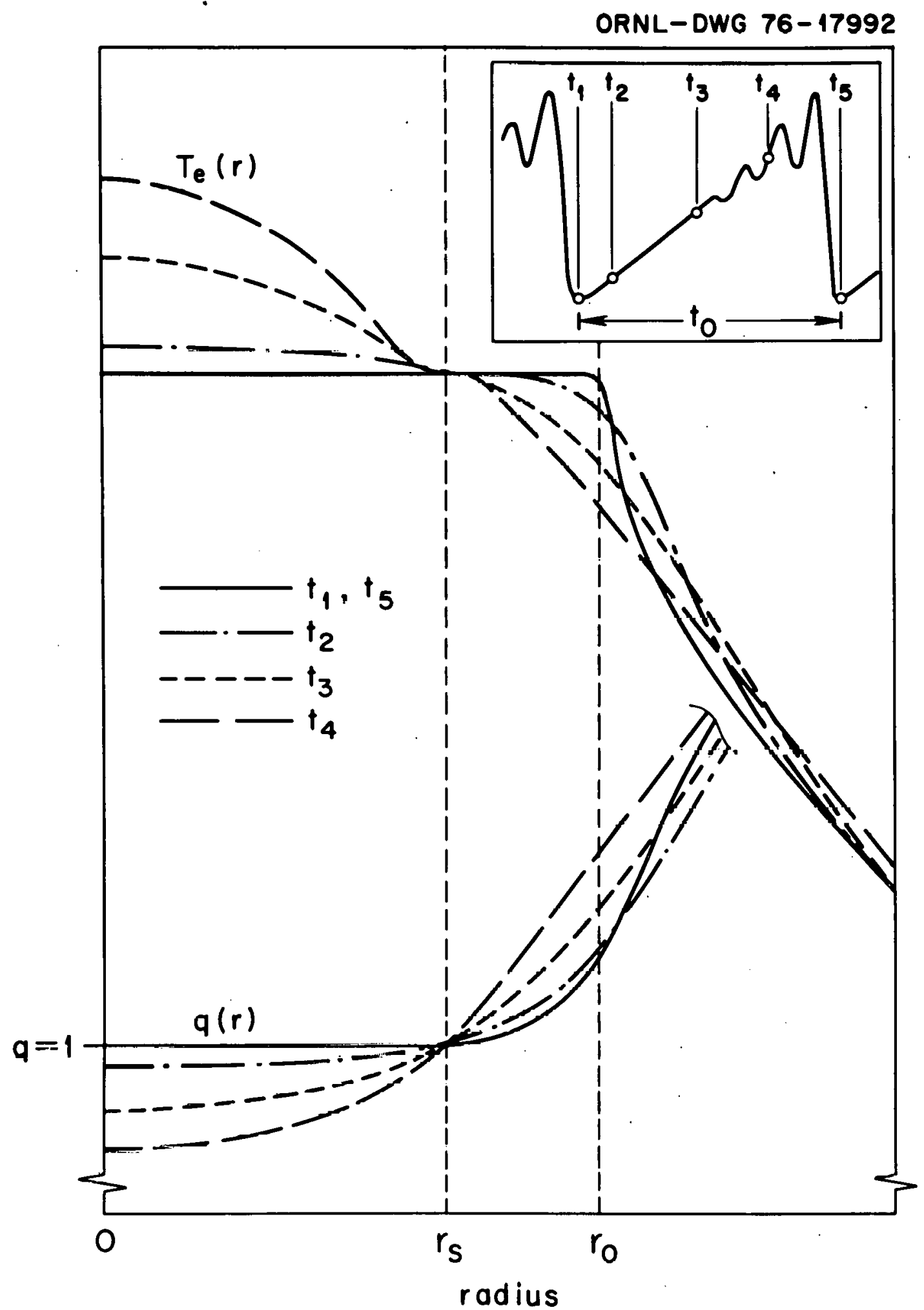

Fig. 1. Sketches of a sawtooth oscillation and the corresponding time evolution of the temperature and safety factor profiles. 
temperature profiles flatten inside the "singular" or "mode rational" surface where the safety factor equals unity. ${ }^{3}$ Recently, it was shown numerically by four independently developed codes that Kadomtsev's model is essentially correct. ${ }^{4-7}$ Specifically, the results presented in Ref. 6 indicate that even in the absence of the pressure gradient term responsible for the internal kink mode, the $m=1$ tearing mode can, in its nonlinear phase, flatten the current density so that the safety factor $q$ becomes approximately equal to unity inside the original $q=1$ singular surface. Furthermore, this process occurs on a time scale consistent with the time for the disruptive part of the sawtooth.

We use the results of Refs. 4-7 to construct a model for sawteeth which is consistent in many respects with experimental, observations. The essential elements of the model are described in Fig. 1, where a schematic diagram of a sawtooth x-ray signal as a function of time is presented. The time evolution of the $m=0$ components of the temperature and safety factor profiles is also sketched at selected times corresponding to the time $t_{1}$ through $t_{5}$ designated in the $x$-ray signal schematic. We assume that at time $t_{1}$ when a given sawtooth begins to rise, the temperature and safety factor profiles inside a radius $r_{0}$ are nearly flat; here $r_{o}$ is some radius greater than the radius $r_{s}$ of the singular surface. Then during the next few hundred microseconds, the heat between $r_{s}$ and $r_{0}$ begins to diffuse away during the time interval $t_{1}-t_{2}$, producing the heat pulse analyzed in Ref. 8. Simultaneously, the plasma inside $r_{s}$ begins to reheat resistively as indicated at time $t_{2}$. As the resistive heating continues during the time interval $t_{2}-t_{4}$, the increase in the temperature produces a decrease in the resistivicy, which leads to an increase in llie curreril and a 
corresponding reduction in the safety factor $q$ to a value less than unity at the origin. Specifically, the poloidal magnetic field evolves through a magnetic diffusion equation, which has a time scale longer than the heating time scale. (The deformation of the q profiles in Fig. 1 is exaggerated for clarity of presentation.) We define $\Delta q=1-q(0)$, where $q(0)$ is the value of the safety factor at the plasma center. As $\Delta q$ increases, the shear at the singular surface increases, and hence the tearing mode growth rate increases until the magnetic island produced by the tearing mode again flattens the temperature, current density, and safety factor profiles during the time interval $t_{4}-t_{5}$. Then the process is repeated.

The assumption that the temperature profile flattens during the time interval $t_{4}-t_{5}$ is. based on our recent results using the code briefly described in Ref. 6 but with the time evolution of the electron temperature included. Numerical results for $q(0)$ initially 0.9 show that the temperature evolves as shown in Fig. 2, where the normalized temperature is plotted as a function of the radius (normalized to the wall radius) along a line through the $x$-point and the center of the $m=1$ magnetic island. The time is normalized to the skin time. The numerical results also indicate that $q(0)$ can perhaps increase to a value slightly greater than one during the disruption, but this fact has not been included in the following analysis.

In order to verify the preceding model by comparison with experiment, we need to explain the following observations:

1) the temperature at which sawteeth occur during a given discharge,

2) the rate at which a sawtooth initially rises, 

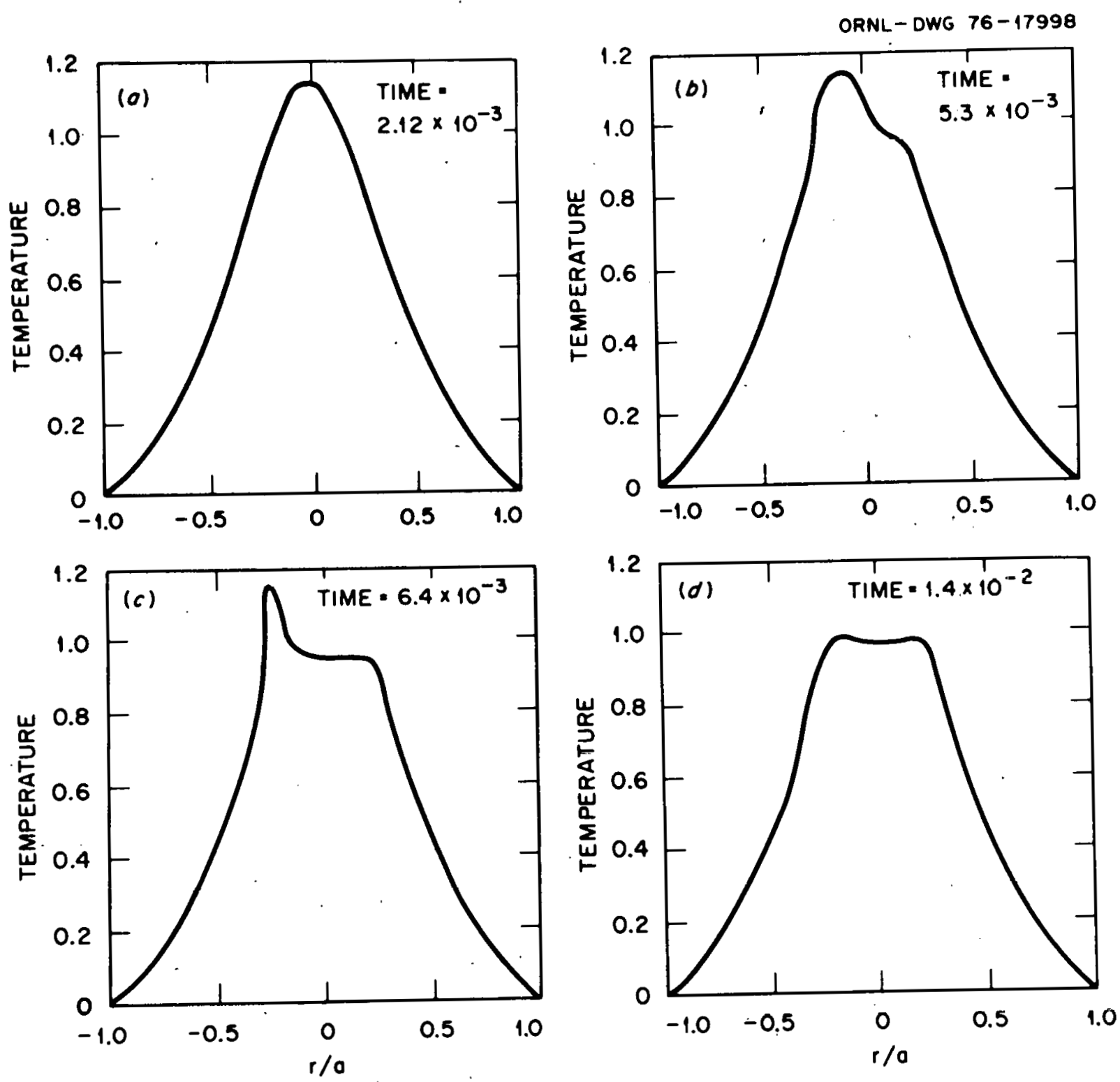

Fig. 2. Numerical code results giving the evolution of the temperature profile as a function of time during the disruption. 
3) the radial dependence of both the amplitude of the $m=1$ oscillations and the amplitude of the sawteeth,

4) the frequency and growth rate of the $m=1$ uscillations preceding the disruptions and the rate at which the growth rate accelerates,

5) the repetition time or period of the sawteeth.

The temperature of the plasma core at which sawteeth occur during a given discharge is consistent with the requirement that $q(0)$ must be less than one for the $m=1$ tearing mode to be unstable. Because

$$
B_{\Theta}=\mu_{0} J_{z} r / 2
$$

and

$$
\eta J_{z}=E_{z}=\frac{V}{2 \pi R}
$$

near the plasma center, requiring that $q(0)=1$ gives

$$
1=\frac{r}{R} \frac{B_{z}}{B_{\theta}}=\frac{2 B_{z}}{\mu_{u} R J_{z}}=\frac{4 \pi B_{z}}{\mu_{u} V} \eta .
$$

Here, ${ }^{B}{ }_{\Theta}$ is the poloidal magnetic field, $\mu_{0}$ is the vacuum magnetic permeability, $J_{z}$ is the toroidal current density, $r$ is the radial coordinate, $n$ is the resistivity, $E_{z}$ is the toroidal electric field, $V$ is the voltage at the limiter, $R$ is the major radius, and $B_{z}$ is the toroidal magnetic field. In relating the voltage at the limiter to the toroidal current density at the plasma center, we have assumed that the toroidal electric field is constant across the plasma. Consequently, if we employ the usual expression for the Spitzer resistivity, Eq. (1) gives an expression for the minimum temperature of the plasma core at which sawteeth occur. In Fig. 3, the temperature predicted by Eq. (1) is compared with the measured temperature 


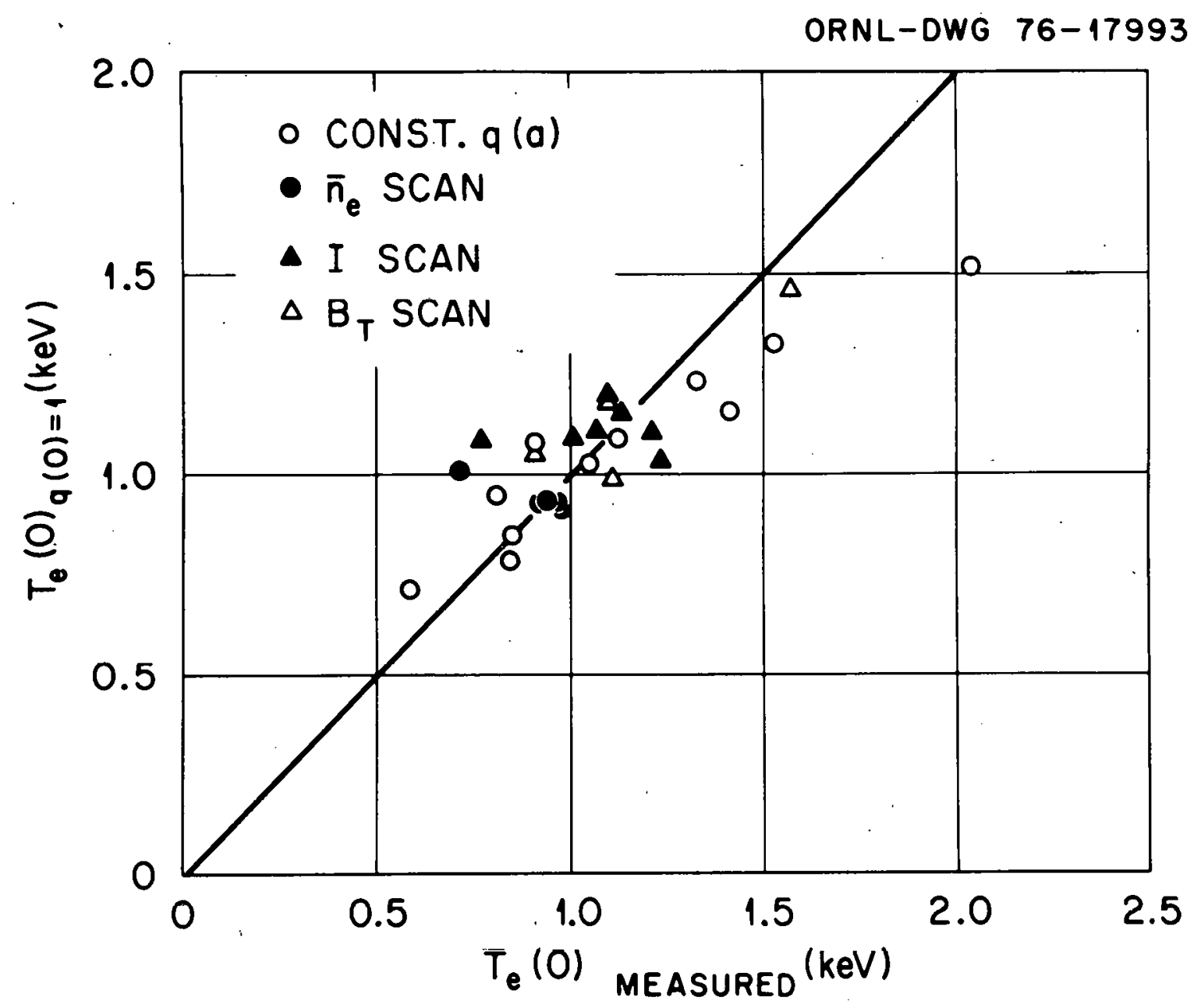

Fig. 3. Comparison of the theoretical and observed electron temperature at which sawteeth begin to occur for various discharges. 
at which sawteeth occur for various discharges. ${ }^{9}$ The agreement is quite good in view of the difficulty in estimating the effective ion charge near the plasma center.

An explanation of the rate at which a sawtooth rises can he obtained through an analysis of the one-dimensional electron heat balance equation

$$
\frac{3}{2} \frac{\partial}{\partial t} n T_{e}=\frac{1}{r} \frac{\partial}{\partial r} r \chi \frac{\partial}{\partial r} T_{e}+n J_{z}^{2}-Q_{e i}+Q_{f e}-Q_{R} \equiv Q .
$$

Here, $\mathrm{n}$ is the particle density, $\mathrm{T}_{\mathrm{e}}$ is the electron temperature, $X$ is the electron thermal conductivity perpendicular to the magnetic field, $\eta \mathrm{J}_{2}{ }^{2}$ is the ohmic heating rate, $Q_{e i}$ is the electron-ion energy transfer rate, $Q_{f e}$ is the fast ion-electron heating rate due to injection, and $Q_{R}$ is the impurity radiation loss rate. Near the plasma center, where the temperature is flat, the transport term should be negligible. Then since the central density $n(0)$ is approximately constant, ${ }^{10}$ the rate at which the electron temperature changes at the plasma center is given by

$$
\left.\frac{\partial T}{\partial t}\right|_{r=0}=\frac{2}{3} \frac{1}{n(0)}\left(n J_{z}^{2}-Q_{e i}+Q_{f e}-Q_{R}\right)_{r=0}
$$

The quantities $\mathrm{nJ}_{\mathrm{z}}{ }^{2}$ and $\mathrm{Q}_{\mathrm{ei}}$ can be easily evaluated in terms of experimental observables. For example,

$$
\mathrm{nJ}_{z}^{2}=\mathrm{E}_{z} \mathrm{~J}_{z}=\frac{\mathrm{V}}{2 \pi \mathrm{R}_{\mathrm{o}}} \mathrm{J}_{\mathrm{z}}
$$

$J_{z}$ is determined by invoking $q(0)=1$. In addition, the time rate of change of the experimental $x$-ray intensity can be converted to the time rate of change of electron temperature. ${ }^{11}$ The quantity $\left.Q_{R}\right|_{r=0}$ is neglected because the concentration of impurities at the plasma core is difficult to ascertain, although often it appears to be small. Consequently, in Fig. 4, the experimental $\partial \mathrm{T}_{\mathrm{e}} /\left.\partial \mathrm{t}\right|_{\mathrm{r}=0}$ is plotted as a function. of the right side of Eq. (3), 


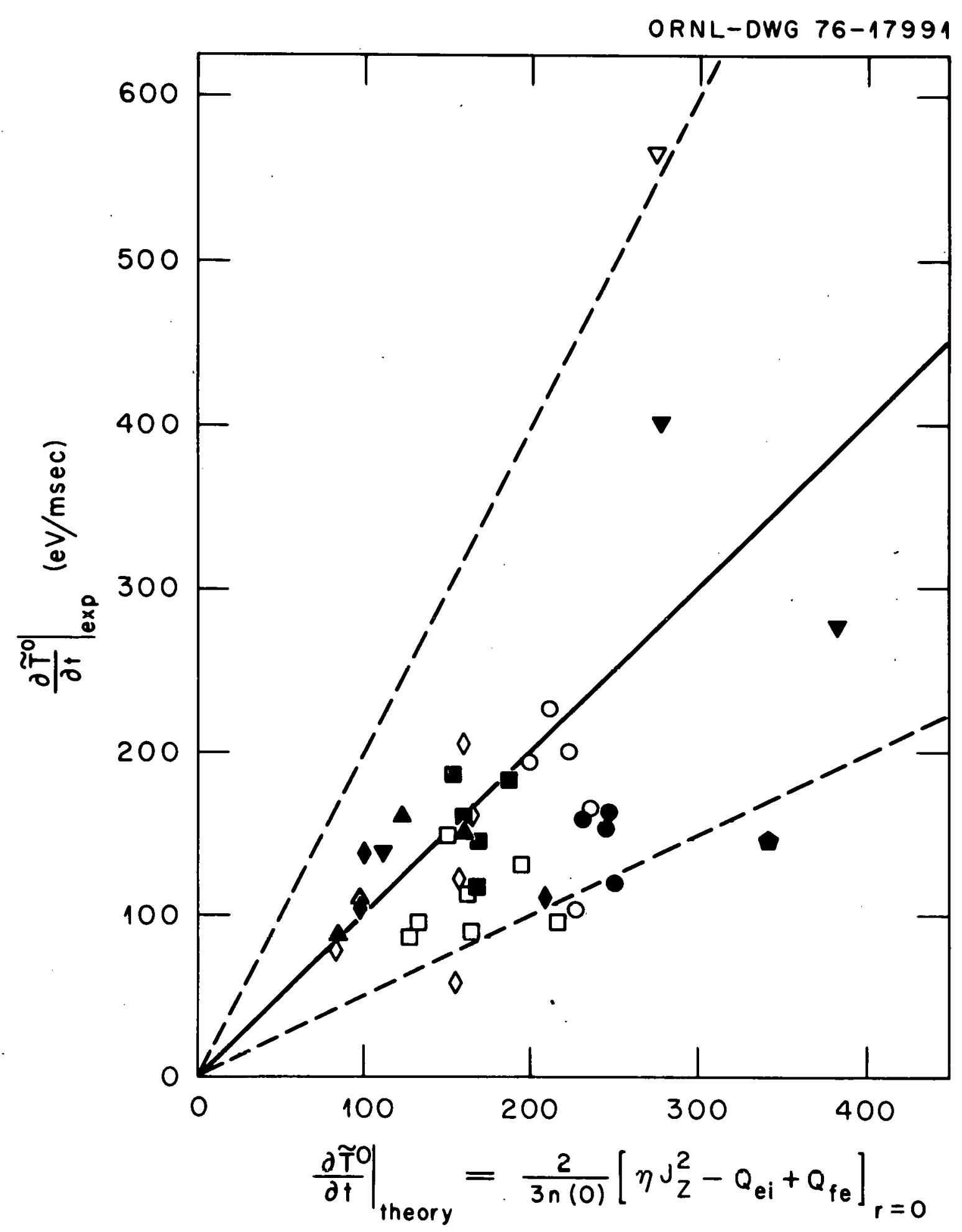

Fig. 4. Comparison of the observed heating rate in the plasma core with the theoretical prediction given by Eq. (3). 
neglecting $Q_{R}$. For the discharges with no injection heating, $Q_{e i}$ is included. On the other hand, for the typically higher density injection heated shots, where the electron and ion temperatures are about equal, $Q_{e i}$ is small and approximately cancels $Q_{f e}$ so that only $n_{z}{ }^{2}$ is plotted. Considering the approximations involved, the agreement between experiment and theory illustrated in Fig. 4 is reasonable.

With respect to the radial dependence of the amplitudes of the oscillations, the experimental results are compared in Fig. 5 with our latest numerical rcsults. The amplitude of the $\mathrm{mi}=1$ temperature oscillations a.s observed in ORMAK ${ }^{11}$ is plotted in Fig. $5(a)$ as a function of chord radius. The singular surface is located at about $8 \mathrm{~cm}$. The observed amplitude $\mathrm{T}_{\mathrm{e}}$ of the sawtooth oscillations is plotted as a function of chord radius in Fig. 5b. In Fig. 5c, the numerically obtained harmonics of the temperature perturbation for small island widths are plotted as a function of the radial coordinate normalized to the radius $r_{w}$ of the wall. The singular surface is located at $r / r_{w}=0.2$. We observe that the shape of the amplitude of the $m=1$ fundamental agrees reasonably well with the observed amplitude. In Fig. 5d, the harmonics of the temperature perturbation are plotted at a time when the temperature and current have become flat. The shape of the dominant $m=0$ component of the temperature also agrees well with the shape of $\hat{\mathrm{T}}_{\mathrm{e}}$, including the phase reversal at the $\mathrm{q}=1$ singular surface. However, if diamagnctic cffects were includel in the numerical algorithm, the structure of the temperature perturbation near the singular surface might change somewhat. Nevertheless, both Fig. 2 and Fig. 5d explicitly indicate the probable origin of the heat pulse analyzed in Ref. 8. 

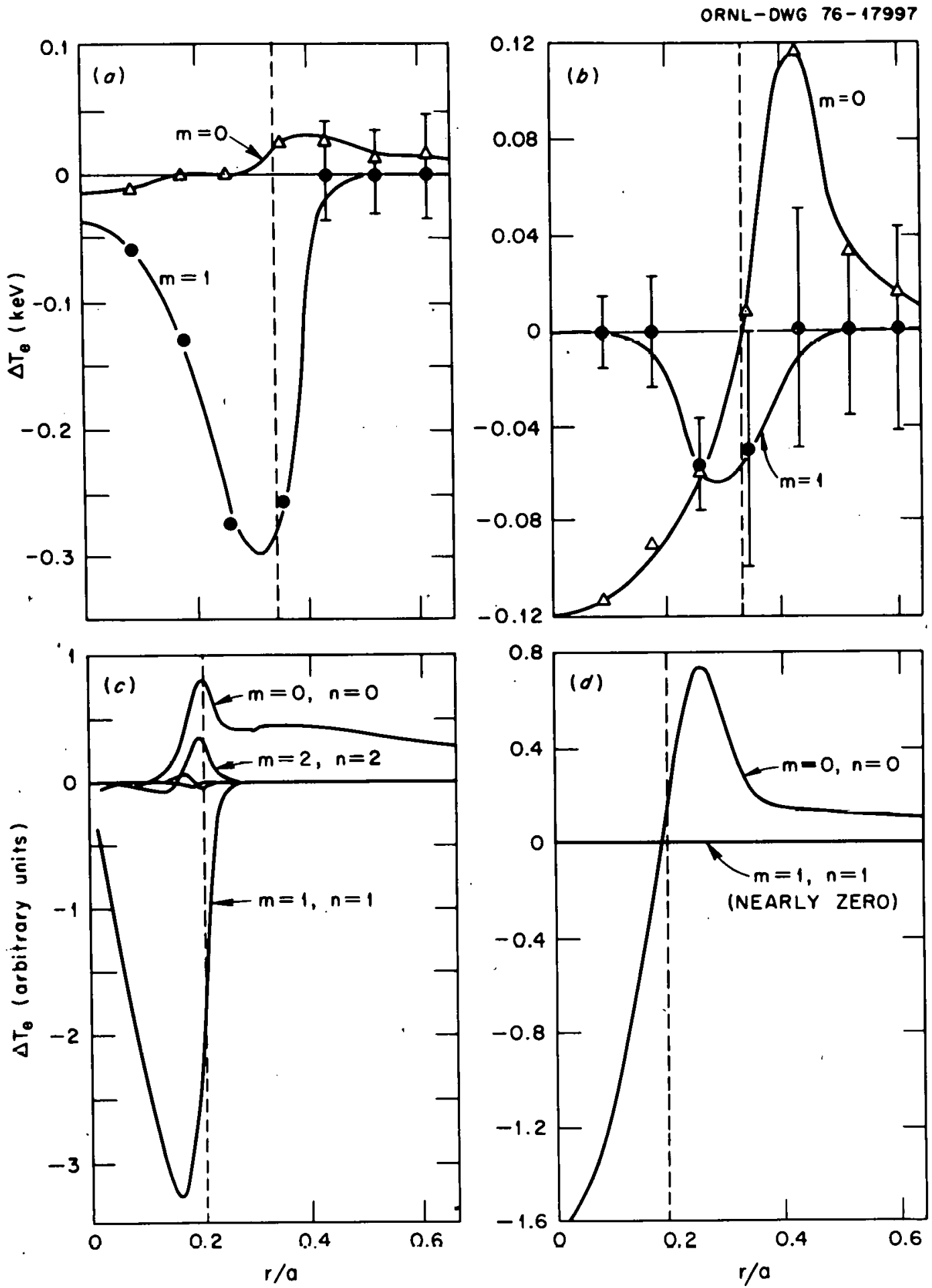

Fig. 5. Comparison of the experimentally observed radial dependence of the $\mathrm{m}=1$ oscillation amplitude and the sawtooth amplitude with the numerical results. (a) Experimental $\mathrm{m}=1$ oscillation amplitude estimated from the $x$-ray amplitude at a time immediately preceding the internal disruption. (b) Experimental sawtooth temperature amplitude just after disruption. (c) Fourier harmonics of the temperature perturbation vs the radial coordinate for small island widths (numerical results). (d) Fourier harmonics of the temperature perturbation vs the radial coordinate at a time when the temperature has become flat (numerical results). 
In order to analyze the growth rate of the $m=1$ oscillations preceding the disruption, we must evaluate the linear growth rate of the tearing mode ircluding diamagnetic cffects, which are not incorporated in the present version of the code. The following expressions for the growth rates were derived employing the low $\beta$, large aspect ratio, cylindrical geometry approximations described in Refs. 4, 6, 12, and 13. These approximations should be valid within the plasma core for ORMAK parameters. Furthermore, the electron-ion collision frequency is much greater than the growth rates of interest, so that a fluid description is reliable. In the absence of diamagnetic drifts and the pressure gradient term responsible for the internal kink mode, the tearing mode growth rate is given by

$$
\gamma_{\mathrm{T}}=\alpha^{2 / 3} /\left(\mathrm{S}^{1 / 3} \tau_{\mathrm{Hp}}\right)
$$

where

$$
\begin{aligned}
& \left.\alpha \equiv \mathrm{r}_{\mathrm{w}} \frac{\mathrm{dq}}{\mathrm{dr}}\right|_{\mathbf{r}_{\mathbf{S}}}, \\
& \mathrm{S} \equiv \tau_{\mathrm{R}} / \tau_{\mathrm{Hp}},
\end{aligned}
$$

$r$ is the radial coordinate, $r_{w}$ is the radius of the wall, $r_{s}$ is the radius of the singular surface, $\tau_{R}\left(\equiv r_{w} 2 / \bar{n}\right)$ is the skin time, $\bar{n}$ is the magnitude of the resistivity, $\tau_{\mathrm{Hp}}\left[\equiv \mathrm{m} \rho^{1 / 2} /\left(\mathrm{kB}_{2}\right)\right]$ is the poloidal MHD time, $\rho$ is the mass density, $\mathrm{k}$ is the toroidal wave number, and $\mathrm{B}_{z}$ is the magnetic field in the toroidal direction. Also, the electron and ion diamagnetic drift frequencies are defined by

$$
\omega_{\star_{i}}=\left.\frac{1}{\mathrm{eB}_{z}} \frac{\mathrm{m}}{\mathrm{nr}_{\mathrm{s}}} \frac{\mathrm{dP} \mathrm{oi}}{\mathrm{dr}}\right|_{r_{s}}
$$

and 


$$
\omega_{*_{e}}=\frac{1}{\mathrm{eB}} \frac{\mathrm{m}}{\mathrm{r}_{\mathrm{s}}}\left(\frac{1}{\mathrm{n}} \frac{\mathrm{dP}}{\mathrm{oe}}+0.71 \frac{\mathrm{dT}_{\mathrm{e}}}{\mathrm{dr}}\right)_{\mathrm{r}_{\mathrm{s}}},
$$

where $e$ is the magnitude of the electron charge, $P_{o i}$ is the total unperturbed ion pressure, $P_{o e}$ is the unperturbed electron pressure, $n$ is the particle density, and $T_{o e}$ is the unperturbed electron temperature. The growth rate $\gamma$ of the tearing mode including diamagnetic drifts $12,14,15$ is given by

$$
r=\mathrm{G} \gamma_{\mathrm{T}} \text {, }
$$

where

$$
\begin{aligned}
& G=z_{1}+z_{2}, \\
& z_{1}=(\bar{z}+1 / 2)^{1 / 3}, \\
& z_{2}=-(\bar{z}-1 / 2)^{1 / 3}, \\
& \bar{z}=\left(\omega_{*} / \gamma_{T}\right)^{6},
\end{aligned}
$$

and

$$
\omega_{\star_{i}}=\omega_{\star_{e}} \equiv \omega_{*}
$$

The electron and ion diamagnetic drift frequencies are taken to be equal for simplicity. In the limit $\gamma<\omega_{*_{i}} / 2, \omega_{*_{e}} / 2$,

$$
\gamma=\frac{\gamma_{\mathrm{T}}{ }^{3}}{\omega_{*_{i}}{ }^{\omega_{*} \mathrm{e}}} \text {. }
$$

The frequency corresponding to the preceding growth rates is simply the Doppler shift due to the bulk toroidal rotation of the plasma. Equations (5) and (6) were obtained in the limit $\left|\gamma_{\mathrm{k}} \tau_{\mathrm{Hp}} / \varepsilon\right|<1$ (see Ref. 12), where $\gamma_{k}$ is the growth rate of the ideal internal kink in the absence of diamagnetic effects and $\varepsilon$ is the tearing layer width. Our estimates indicate that this is the appropriate limit for ORMAK parameters.

From the preceding expressions for the growth rate, we see that it is necessary to compute the shear parameter $\alpha$, which in turn requires the 
calculation of the poloidal magnetic field $B_{\Theta}$. As implied by our model, $\mathrm{B}_{\Theta}$ and $\alpha$ are in general functions of time. We assume that the $m=0$ components of $\mathrm{B}_{\Theta}$ and the temperature $\mathrm{T}_{e}$ evolve independently of the tearing mode activity over a sufficient length of time so that they can be described by a one-dimensional equation in the radial coordinate. Combining Faraday's law and Ohm's law, we obtain the equation for $\mathrm{B}_{\theta}$

$$
\frac{\partial B_{\Theta}}{\partial t}=\frac{\partial}{\partial r} \eta J_{z}
$$

where $\eta$ is the resistivity and $J_{z}$ is the tornidal current density. We linearize all quantities about the profiles pictured in Fig. 1 at time $t_{2}$ and restrict our attention to the region enclosed by the singular surface $r_{s}$. We denote the unperturbed quantities at time $t_{1}$ by "o" subscripts and the perturbed quantities by tildes. Then selecting the dominant contributions due to the perturbed resistivity and noting that. $\tilde{\eta}_{0}=\left(a n_{0} / \lambda T_{e o}\right)$ $\varlimsup_{e}^{o}=-(3 / 2)\left(\eta_{o} / T_{e o}\right) \Psi_{e}^{o}$ and that the unperturbed electric field $n_{o} J_{z o}$ is approximately constant, we obtain

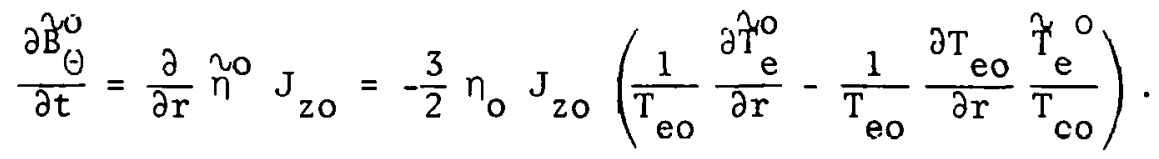

Here, the "o" superscripts indicate that only the $m=0$ components of the perturbed quantities are being treated. Thus, in order to calculate $\widetilde{\mathrm{B}}_{\Theta}^{\circ}$, the perturbation in the electron temperature must be calculated. Wc also observe that because Eq. (8) is a magnetic diffusion equation, $\widetilde{\mathrm{B}}_{\theta}{ }^{0} / \mathrm{B}_{\theta o}$ ح $\left(t / \tau_{R}\right)\left(r_{w} / r_{s}\right)^{2}\left(T_{e}^{o} / T_{e o}\right) ; i . e$, a significant temperature perturbation does not produce a large change in $B_{\theta}$ and hence $q$. This means that the growth rate is smaller than one might expect although, as we shall show, frequently it is rapidly growing in time. Because 


$$
q(r, t) \approx q_{0}^{\prime}(r)\left(1-\tilde{B}_{\Theta}^{o} / B_{\Theta_{0}}\right)
$$

and because $\partial \widetilde{B}_{\theta} / \partial t$ must vanish at the $q=1$ singular surface, we can immediately obtain an equation for $\alpha$, namely

$$
\frac{\partial \alpha}{\partial t}=\frac{3}{2} r_{w} \frac{q_{o}}{B_{\Theta_{0}}} \frac{\eta_{0} J_{z o}}{T_{c o}\left(r_{s}\right)}\left(\frac{\partial^{2} \stackrel{\tau}{T}_{e}^{o}}{\partial r^{2}}\right)_{r_{s}}
$$

For the case of interest, Eq. (2) cannot be solved for $\mathrm{T}_{e}^{\mathrm{o}}(\mathrm{r}, \mathrm{t})$ in closed form. In addition, we wish to focus our attention on correlation of the growth rate with experiment rather than on the evolution of the temperature perturbation. Consequently, using experimental observations, we construct a model for $\widetilde{T}_{e}^{o}(r, t)$. As previously argued, the data indicate that the temperature at the plasma center increases linearly with time. Furthermore, as illustrated by discharge 13477 in Ref. 8 , the radius $r_{s}$ of the $q=1$ singular surface does not appear to change significantly with time, and the $m=0$ component of the temperature perturbation vanishes at this surface. Therefore, Eq. (8) implies that $\left.\frac{\partial \mathcal{T}^{\circ}}{\partial \mathrm{r}}\right|_{r_{s}}$ vanishes. Thus, as a model for $\mathfrak{T}_{e}^{0}$, we write

$$
\tilde{\mathrm{T}}_{\mathrm{e}}^{0}-\tilde{\mathrm{T}}_{\mathrm{e}}^{0}(0, t)\left(1+a \mathrm{r}^{2}+b r^{3}\right) \text {, }
$$

where

$$
\widetilde{T}_{e}^{o}(0, t)=T_{e o} t / \tau_{h}
$$

and the heating time $\tau_{h}$ is given by

$$
\tau_{h}=\left(3 / 2 n T_{e o}\right) / Q
$$

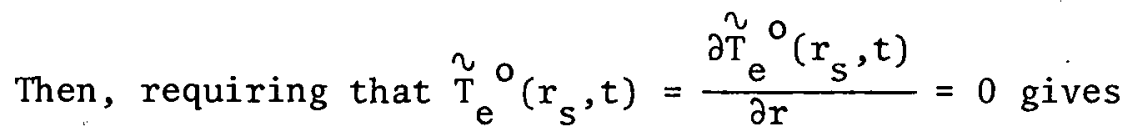




$$
\dddot{T}_{e}^{o}(r, t)=\widetilde{T}_{e}^{o}(0, t) \quad\left[1-3\left(r / r_{s}\right)^{2}+2\left(r / r_{s}\right)^{3}\right] .
$$

Now, using Eq. (9), we immediately obtain

$$
\alpha=\alpha_{0}+\bar{\alpha} t^{2}
$$

where $\alpha_{0}$ is the initial or unperturbed value of $\alpha$ and

$$
\bar{\alpha}=9 \frac{q_{n}}{{ }_{\theta_{0}}} \frac{r_{w}}{r_{s}^{2}} \frac{\eta_{0} J_{z o}}{\tau_{h}} .
$$

As we shall later show, the growth rate of the $m=1$ oscillations is too small to be explained by $\gamma_{\mathrm{T}}$, the tearing mode growth rate in the absence of diamagnetic drifts. Thus, using Eq. (6), which includes diamagnetic effects and implies that $\gamma<\gamma_{\mathrm{T}}$ since $\gamma_{\mathrm{T}}<\omega_{*_{i}}$, $\omega_{\star_{e}}$, we see that

$$
\gamma=\frac{\left(\bar{\alpha}_{o}+\bar{\alpha} t^{2}\right)^{2}}{\omega_{\star_{i}} \omega_{\star_{e}} \tau_{\mathrm{Hp}}{ }^{2} \tau_{\mathrm{R}}} .
$$

The total electron temperature $\mathrm{T}_{e}$ and the corresponding $\mathrm{x}$-ray intensity $\mathrm{I}$ can be written as

$$
\mathrm{T}_{e}=\mathrm{T}_{\mathrm{eo}}+\widetilde{T}_{\mathrm{e}}^{0}+\widetilde{T}_{\mathrm{e}}^{1}
$$

and

$$
1=\mathrm{I}_{0}+\mathrm{H}^{0}+\mathrm{I}^{1}
$$

where the "o" subscript indicates the unperturbed value, the tilde indicates the perturbation, and the " $O$ " and " 1 " superscripts respectively indicate the $\mathrm{m}=0$ and $\mathrm{m}=1$ components of the perturbation. In general, for a given chord

$$
I=F\left(T_{e}\right) \text {, }
$$

where $F$ is a complicated function, and thus 


$$
\mathcal{I}^{1}=\left.\widetilde{T}_{e}^{1} \frac{\partial \mathrm{F}}{\partial \mathrm{T}_{e}}\right|_{T_{e}}=\mathrm{T}_{e o}+\widetilde{T}_{\mathrm{e}}^{\mathrm{o}}
$$

Consequently, denoting the initial value by the subscript $i$,

$$
\frac{\Upsilon^{1}}{Y_{i}} \simeq \frac{\widetilde{T}_{e}^{1}}{\widetilde{T}_{e i}} \text {, }
$$

since the change in $\widetilde{T}_{e}^{0}$ is small compared to $\mathrm{T}_{e o}$. Therefore,

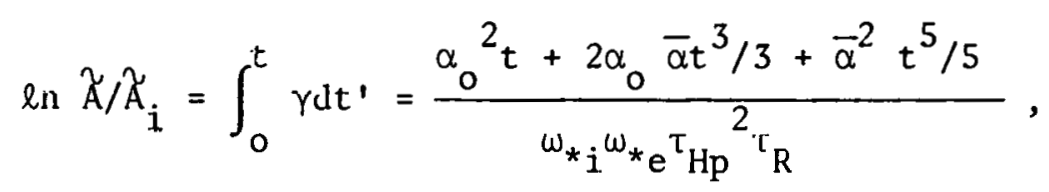

where $\tilde{A}$ is the magnitude of the $m=1$ oscillation in the $x$-ray intensity at time $t$ and $\tilde{A}_{i}$ is the initial intensity at $t=0$. The terms responsible for driving the internal kink mode could also possibly contribute to the growth rate in a way such that $\alpha_{0}$ in Eq. (2) would effectively increase. However, within the accuracy of our measurements, it is unnecessary to include this effect.

Then, if $\alpha_{0}$ dominates,

$$
\ln \tilde{A} / \tilde{A}_{i}=\gamma_{0} t \text {, }
$$

where

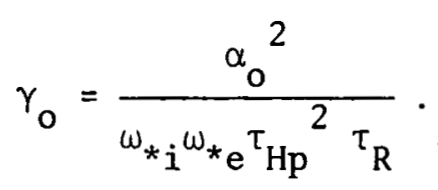

For $\gamma_{T} \gtrsim \omega_{*_{i}} / 2 \sim \omega_{*} e^{/ 2}$, Eq. (5) should be used to evaluate $\gamma_{0} \cdot$ On the other hand, if the $\bar{\alpha}$ term is dominant, then

$$
\ln \tilde{\AA} / \AA_{i}=C t^{5},
$$

where 


$$
\begin{aligned}
& C=\frac{\bar{a}^{2}}{5 f \tau_{H p}{ }^{2} \tau_{R} \bar{\omega}_{*}^{2}}, \\
& f=1.71 \mathrm{~T}_{i} / T_{e},
\end{aligned}
$$

and

$$
\bar{w}_{*}=\left.\frac{m}{\mathrm{e}_{z} \mathrm{r}_{\mathrm{s}}} \frac{\mathrm{dT} \text { eo }}{\mathrm{d} r}\right|_{r_{s}}
$$

Assuming that the safety factor $q$ increases linearly from the magnetic axis to the singular surface, we estimate that

$$
\alpha_{0} \approx r_{w}\left[\frac{1-q\left(0, t_{0}\right)}{r_{s}}\right]=\frac{9}{2} \frac{n_{0} J_{z o}}{D_{\theta_{0}}\left(r_{s}\right)} \frac{r_{w}}{r_{s}{ }^{2}} \frac{t_{0}{ }^{2}}{\tau_{h}} .
$$

where $t_{0}$ is the repetition time. The quantity $B_{\Theta_{0}}\left(r_{s}\right)$ can be evaluated by observing that $J_{z o}$ is essentially constant inside $r_{s}$ so that $B_{{ }_{0}}\left(r_{s}\right)=$ $\mathrm{J}_{\mathrm{og}} / 2$. In order to obtain $\left|\bar{\omega}_{*}\right|$, we estimate that $\mid \partial \mathrm{T}$ eo $/ \partial \mathrm{r} \mid$ is given by. $\hat{\mathrm{T}}_{\mathrm{e}} / \mathrm{r}_{s}$, where the sawtooth amplitude $\hat{\mathrm{T}}_{c}$ is given by $\hat{\mathrm{T}}_{e}=\overbrace{\mathrm{T}}^{0}\left(0, t_{y}\right)=$ $\mathrm{T}_{\text {eo }} t_{0} / \tau_{h}$. The hcating time $\tau_{h}$ is taken directly from experiment.

In Fig. 6a, $\tilde{A}$ for different chords is plotted on a semilogarithmic grid as a function of $t$ for ORMAK discharge number 11141; in Fig. 6b, $\check{A}$ for different chords is plotted as a function of $t^{5}$ for ORMAK discharge number 13477. We conclude that for discharge 11141, $\alpha_{0}$ is dominant, while for discharge 13477, $\bar{\alpha}$ is dominant. In Fig. 7, $\AA$ for the chord passing nearest to the singular surface is plotted as a function of both $t$ and $t^{5}$. The time is normalized to the maximum value of $t$ for which $\tilde{A}$ was measured, and $\tilde{X}$ has been scaled to facilitate the presentation. We observe that some 


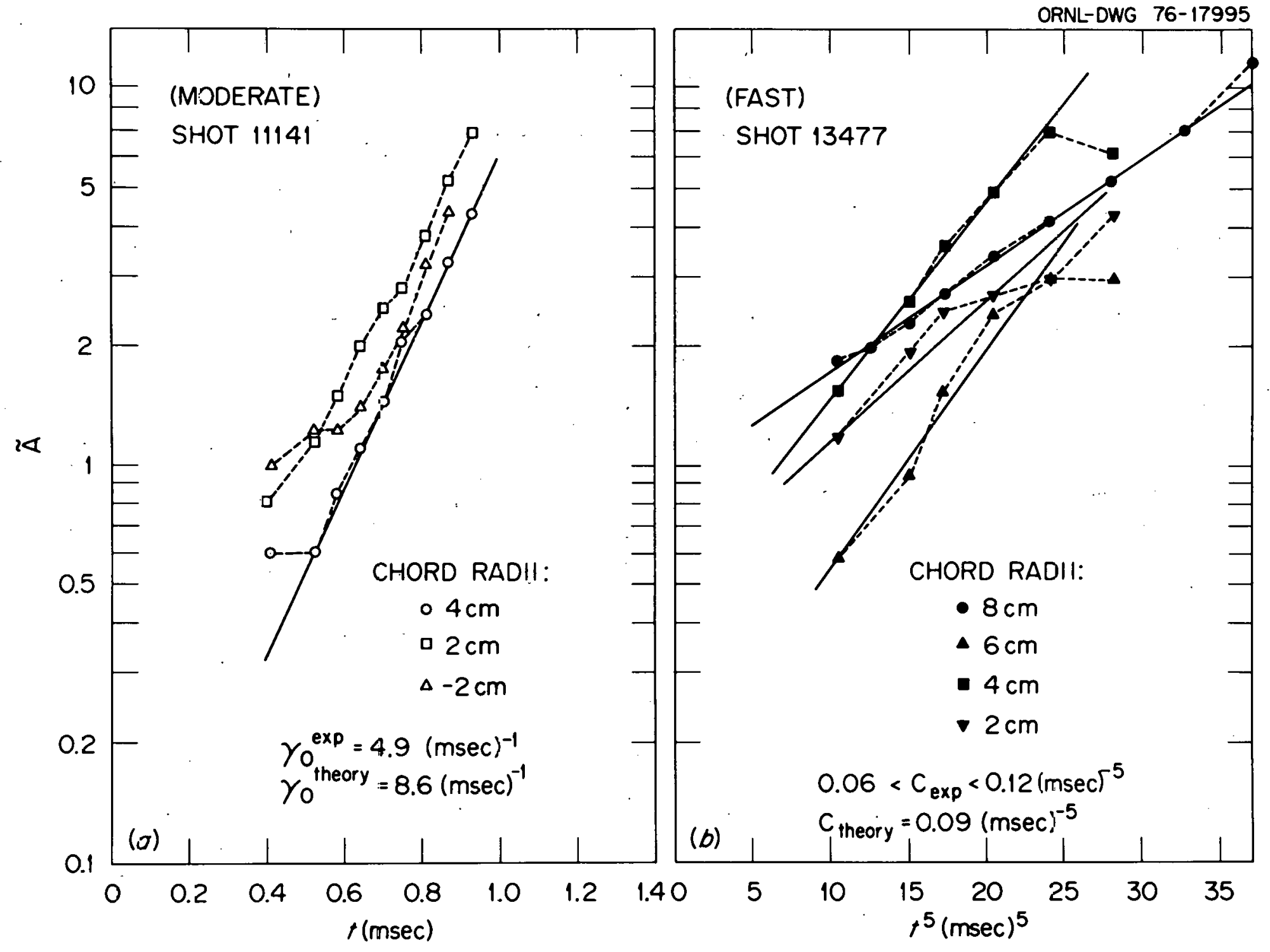

Fig. 6. (a) The amplitude of the $m=1$ oscillations for various shords as a function of $t$ for Shot 11141. (b) The amplitude of the $m=1$ oscillations for various chords as a function of $t^{5}$ for Shot 13477 . 


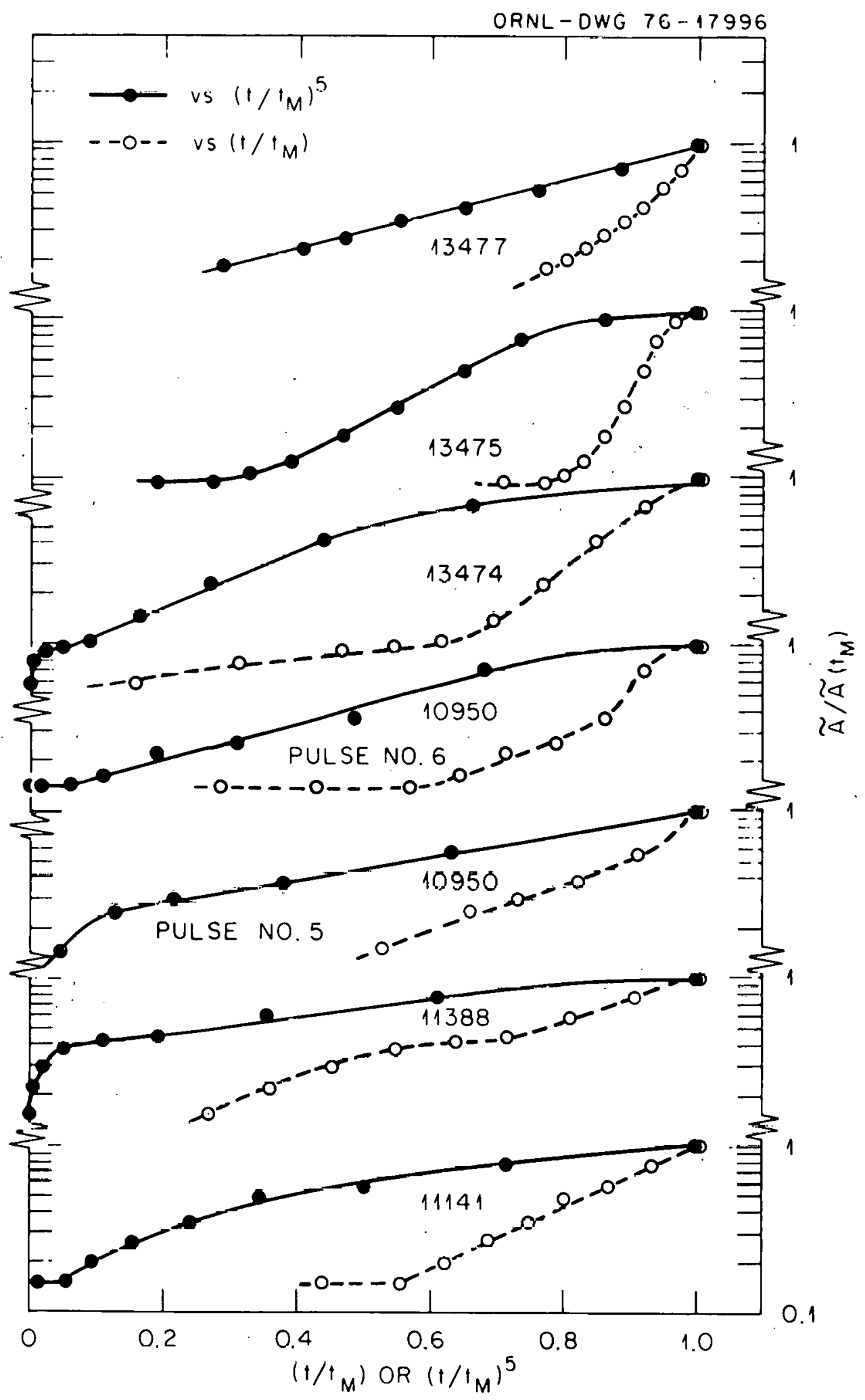

Fig. 7. Normalized amplitude of the $m=1$ oscillations (for various discharges) for the chord nearest the singular surface vs $t / t_{M}$ and $\left(t / t_{M}\right)^{5}$, where $t_{M}$ is the largest time for which the amplitude was measured. 
discharges exhibit clearly a $t$ or $t^{5}$ dependence while others show what can be interpreted as a transition from $t$ to $t^{5}$ behavior.

In Table 1, the theoretical and experimental values of $\gamma_{0}$ and $C$ are compared for various discharges. We conclude that when $\ln \tilde{A}$ is clearly. proportional to $t$, the theoretical $\gamma_{0}$ agrees well with experiment, while for the cases where $\ln \tilde{A}$ is clearly proportional to $t^{5}$, C agrees. well with experiment. Furthermore, the growth rate $\dot{\gamma}_{\mathrm{T}}$ for the tearing mode in the absence of diamagnetic drifts is consistently too large to explain the data, which is to be expected since the estimated diamagnetic frequency exceeds the experimental growth rate. We also note that for all the discharges which are heated by neutral beam injection, $\ln \tilde{A}$ is essentially proportional to $t^{5}$ and, as indicated in Table 1 , the growth of the $m=1$ oscillations can be described as "fast." This correlation is consistent with the experimental observation that neutral beam injection often flattens the temperature and density profiles somewhat and thus perhaps decreases the shear parameter $\alpha$, On the other hand, for discharges which are only heated resistively, $\ln \tilde{A}$ is sometimes proportional to $t$ and the growth of $m=1$ oscillations can be described as "slow." Often, however, resistively heated shots exhibit some $t^{5}$ dependence for large $t$ and the growth of the $m=1$ oscillations is characterized as "moderate." It should be emphasized that the designation fast, moderate, or slow refers to the rate at which the $m=1$ growth rate changes.

Thus, it appears that the growth of the $m=1$ oscillations can be explained by elementary tearing mode theory. Unfortunately, however, the magnitude of the frequency cannot be predicted precisely. As argued in Kef. 12 , a reasonabie hypothesis is that the frequency is simply the 
Tab:e 1. Comparison of theoretical and experimental values of $c$ and $\gamma$

\begin{tabular}{|c|c|c|c|c|c|c|c|c|}
\hline Discharge & $\begin{array}{l}\mathrm{C}_{\text {theory }} \\
\text { (msec) }\end{array}$ & $\begin{array}{c}\mathrm{C}_{\mathrm{e}=\mathrm{p}} \\
(\mathrm{msec})^{-5} \\
\end{array}$ & $\begin{array}{l}\gamma_{0} \text { theory } \\
\text { (msec) }{ }^{-1} \\
\end{array}$ & $\begin{array}{c}\gamma_{0} \exp \\
(\text { msec })^{-1} \\
\end{array}$ & $\begin{array}{l}\text { Description } \\
\text { of growth } \\
\text { of } m=1 \\
\text { oscillations } \\
\end{array}$ & $\begin{array}{c}\text { Basic time } \\
\text { dependence } \\
\text { of } \\
\ln \AA / \tilde{A}_{i} \\
\end{array}$ & $\begin{array}{c}\gamma_{\mathrm{T}} \\
\text { (msec) }^{-1} \\
\end{array}$ & Injection \\
\hline .13477 & 0.09 & $0.06-0.12$ & 1.4 & $3-6$ & fast & $t^{5}$ & 11 & Yes \\
\hline $\begin{array}{l}10950 \\
\text { Pulse }\end{array}$ & 23 & $7-25$ & 6 & $3-12$ & slow & $\left.\stackrel{t}{t} t^{5}\right)$ & 22 & No \\
\hline $\begin{array}{l}10950 \\
\text { Pulse }\end{array}$ & 23 & $6-7$ & 6 & 1 & moderate & $\begin{array}{l}\text { combi- } \\
\text { nation }\end{array}$ & 22 & No \\
\hline 13474 & 0.11 & 0.14 & 2 & 0.6 & fast & $t^{5}$ & 9 & Yes \\
\hline 11411 & 15 & $2-3$ & 9 & 5 & moderate & $t$ & 26 & No \\
\hline 11388 & 15 & $9-11$ & 6 & 4 & moderate & $\begin{array}{l}\text { combi- } \\
\text { nation }\end{array}$ & $\therefore 18$ & No \\
\hline
\end{tabular}


Doppler shift due to the bulk rotation of the plasma, which is not described by the equations in Ref. 12 and about which little is known, although there is evidence that the plasma does rotate toroidally. 16

This situation, however, prompts us to consider another limit of the dispersion relation as discussed in Ref. 12. In the limit where $\gamma_{k}<0$ and $\left|\gamma_{k} \tau_{H p} / \varepsilon\right|>1$, the growth rate $\gamma$ of the instability is given by

$$
\gamma=2^{1 / 3} \frac{\gamma_{T}{ }^{3}}{\left(\gamma_{k}{ }^{4} \omega_{*_{i}}{ }^{\omega_{*_{e}}}\right)^{1 / 3}}
$$

and the frequency is $\omega_{*_{e}}$ (without a Doppler shift). Although the frequency is qualitatively correct, we conclude that the limit does not apply to ORMAK for several reasons. First, although both the sign and the magnitude of $\gamma_{\mathrm{k}}$ in toroidal geometry are in dispute, ${ }^{17,18}$ it appears that even if $\gamma_{\mathrm{k}}<0$ for ORMAK, $\left|\gamma_{\mathrm{k}} \tau_{\mathrm{Hp}} / \varepsilon\right|<1$. Second, because it is shown in Refs. 17 and 18 that $\gamma_{k}$ is proportional to $\alpha^{-1}$, the growth rate as given by Eq. (10) is proportional to $\alpha^{10 / 3}$, which implies a possible $t^{23 / 3}$ dependence for ln $\tilde{A} / \tilde{A}_{i}$. There is no evidence of such a rapid time dependence in ORMAK. It should be pointed out, however, that a more accurate determination of $\gamma_{k}$ in toroidal geometry might show that $\gamma_{k}$ is proportional to $\left(\alpha+\alpha_{c}\right)^{-1}$, where $\alpha_{c}$ is constant. If $\alpha_{c}$ were large enough, this would imply a $t^{5}$ time dependence for $\ln \tilde{A} / \AA_{i}$ and, consequently, one would have difficulty determining the appropriate limit of the dispersion relation for ORMAK.

An additional important caveat is that one can also argue that coupling between the $m=1$ and $m=2$ tearing type modes might also result in an accelerating growth rate. This point is presently under investigation. 
Finally, we return to Eq. (6) for our expression of the growth rate and use it to calculate the repetition time of the sawteeth. An inspection of a large number of discharges indicates that for a clear majority of the cases, the growth of the $m=1$ oscillations can be described as fast or moderate, so that we expect $\ln \tilde{A}$ to be proportional to $t^{5}$ at least for large $t$. Consequently, in order to determine an expression for the repetition time $t_{0}$, we consider the limit in which $\bar{\alpha}$ dominates $\alpha_{0}$. Then denoting the initial (final) island width by $w_{i}\left(w_{f}\right)$, we have

$$
\ln w_{f} / w_{i}=\frac{1}{2} \int_{0}^{t_{0}} \gamma(t) d t=\frac{1}{2} C t_{0}^{5} \text {. }
$$

In the preceding equation, $t_{0}$ is determined by observing that it is the time at which $w$ becomes approximately equal to $r_{s}$. Therefore,

$$
t_{0}=\overline{D t}
$$

where

$$
\tau=\left(\frac{1}{19} \ln w_{f} / w_{i}\right)^{1 / 5}
$$

and

$$
\bar{\tau}=\left(\begin{array}{l}
r_{s} \\
r_{w}
\end{array}\right)^{0 / 5}\left(\begin{array}{c}
T_{i} \\
T_{e}
\end{array}\right)^{1 / 5} \tau_{H p}^{2 / 5} \tau_{h}^{2 / 5} \omega_{*}^{2 / 5} \tau_{R}^{3 / 5}
$$

Since the quantity $D$ is very weakly dependent on the radius of the singular surfacc, we takc it to bc constant. In Fig: 8, the experimental repetition time is plotted as a function of $\bar{t}$. The experimental slope $D$ is 0.73 (msec) $^{-1}$. If we take $w_{f}$ to be between $r_{s}$ and $2 r_{s}$, or about $8 \mathrm{~cm}$, and $w_{i}$ to be between one tenth of the tearing layer width $(0.01 \mathrm{~cm})$ and the tearing

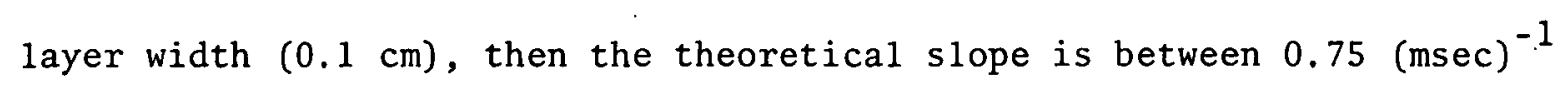




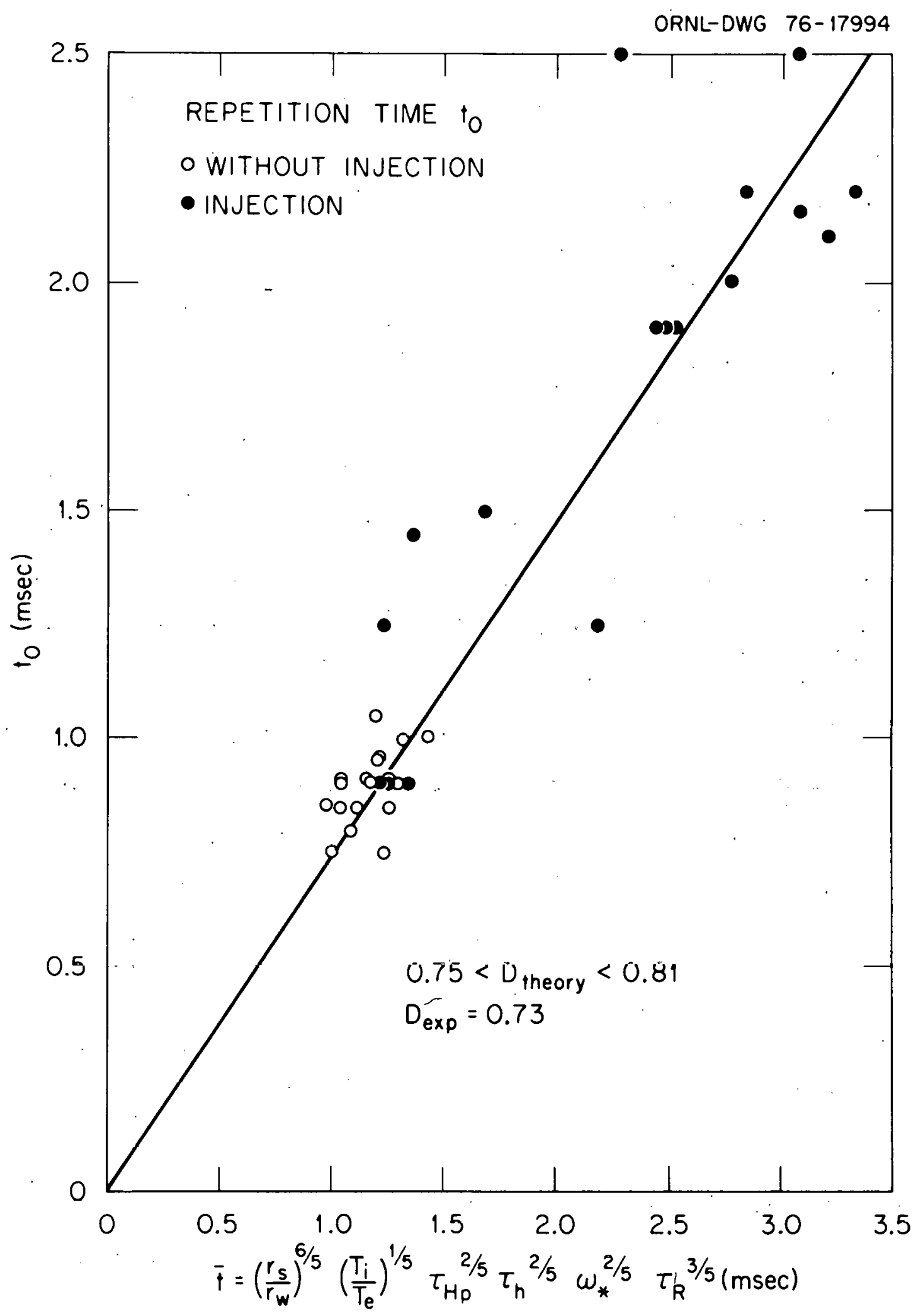

Fig. 8. Experimental sawtooth repetition time compared with the theoretical prediction given by Eq. (11). 


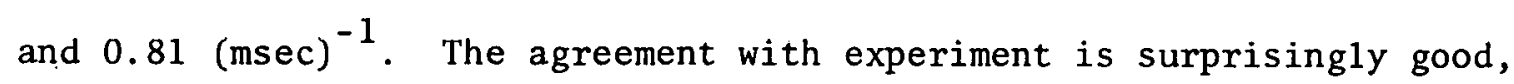
considering the assumption that $\bar{\alpha}$ dominates $\alpha_{0}$ for all shots. Since $t_{0}$ is used to estimate $\omega_{*}$, Eq. (11) is an implicit formula for $t_{0}$. If we solve explicitly for $t_{0}$, we obtain

$$
t_{o}=d\left(\bar{n} \bar{B}_{z} \bar{T}_{i} \bar{T}_{e} \bar{r}_{s}^{2} \bar{R}^{2} / \bar{V}^{3}\right)^{1 / 3} \mathrm{msec},
$$

where

$$
d=13\left(\ln w_{f} / w_{i}\right),
$$

$\bar{n}$ is the density in units of $10^{13} \mathrm{~cm}^{-3}$ at the $q=1$ singular surface, $\bar{B}_{z}$ is the magnetic field in tesla, $\overline{\mathrm{T}}_{i}$ and $\overline{\mathrm{T}}_{\mathrm{e}}$ are the electron and ion temperatures in kiloelectron volts at the singular surface, $\bar{r}_{s}$ is the radius of the singular surface in meters, $\bar{R}$ is the major radius in meters, and $\bar{V}$ is the voltage in volts. The theoretical value of $d$ is about $20-25$; the experimental value is 19 .

The preceding arguments and comparisons with experiment support the concept that sawtooth oscillations are the result of a cyclic process in which the plasma core is resistively heated until the safety factor drops below unity, causing the tearing mode to become unstable, to grow with an accelerating growth rate, and ultimately to flatten the electron temperature and safety factor profiles. The requirement that the safety factor near the plasma center must be less than unity in order for the tearing mode to become unstable is consistent with the electron temperature of the plasma core at which sawteeth occur. Although the frequency cannot be predicted precisely, the agreement between the theoretical and experimental growth of the $m=1$ oscillations is reasonable, considering the accuracy to which the relevant quantities can be calculated. The rapid rate at which the growth rate often increases can be explained by the rapid rate of 
change of the shear at the singular surface. Furthermore, the radial dependence of the $m=1$ oscillations and the sawtooth oscillations agrees well with the numerical results. Finally, the theoretical prediction for the repetition time of the sawteeth agrees very well with the experimental observations. 


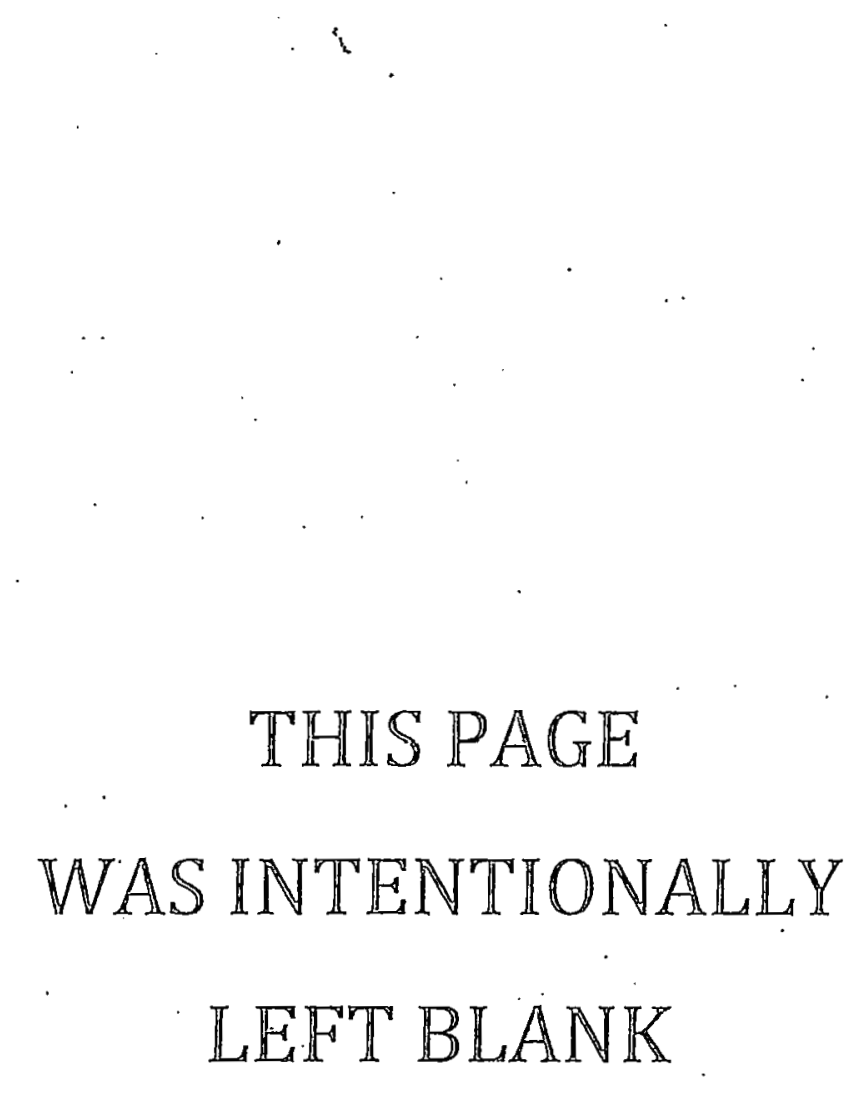




\section{ACKNOWL.EDGMENTS}

The development of this model was stimulated in part by a discussion between one of the authors (J.D. Callen) and Yu. N. Dnestrovskii during a U.S.-Soviet exchange visit. The inclusion of the time evolution of the electron temperature in the code described in Ref. 6 was carried out primarily by D. A. Monticello and R. B. White at the Princeton Plasma Physics Laboratory. The authors thank M. Murakami and J. Harris for providing Fig. 3. They also express their appreciation to M. N. Rosenbluth, J. L. Dunlap, and G. Bateman for several useful discussions and for constructive criticism of the original manuscript. 
THIS PAGE

WAS INTENTIONALLY

LEFT BLANK 


\section{REFERENCES}

1. S. von Goeler, W. Stodiek, and N. Sauthoff, Phys. Rev. Lett. $\underline{33}, 1201$ (1974) .

2. M. N. Rosenbluth, R. Y. Dagazian, and P. H. Rutherford, Phys. Fluids 16, 1894 (1973).

3. B. B. Kadomtsev, Fizika Plazmy 1 , 710 (1975).

4. A. F. Danilov, Yu. N. Dnestrovskii, D. P. Kostomarov, and A. M. Popov, Fizika Plazmy 2, 167 (1976).

5. A. Sykes and J. A. Wesson, Phys. Rev. Lett. $\underline{37}, 140$ (1976).

6. B. V. Wadde11, M. N. Rosenbluth, D. A. Monticello, and R. B. White, Nucl. Fusion 16, 528 (1976).

7. Masafumi Azumi, Japan Atomic Energy Research Institute, Ibaraki, Japan (1976), private communication.

8. J. D. Callen and G. L. Jahns, "Experimental Measurement of Electron Heat Diffusivity in a Tokamak," ORNL/TM-5481, Oak Ridge National Laboratory, Oak Ridge, Tennessee (June, 1976); also published in Phys. Rev. Lett. $\underline{38}, 491$ (1977).

9. Thermonuclear Division Annual Progress Report for Period Ending December 31, 1975, ORNL-5154, Oak Ridge National Laboratory, Oak Ridge, Tennessee (June, 1976).

10. TFR Team, Paper A8 in Proc. Sixth International Conference on Plasma Physics and Controlled Nuclear Fusion Research (1976).

11. J. L. Dunlap, G. L. Jahns, and J. H. Harris, Bu11. Am. Phys. Soc. II 20, 1255 (1975); J. L. Dunlap et a1., to be published. 
12. G. Laval, B. V. Wadde1l, and M. N. Rosenbluth, paper presented at the 1976 Annual Meeting on the Theoretical Aspects of Controlled Nuclear Fusion, Madison, Wisconsin, April 7-9, 1976; to be published elsewhere.

13. M. N. Rosenbluth, D. A. Monticello, H. Strauss, and R. B. White, Phys. Fluids $\underline{19}, 1987$ (1976); also Proc. Fifth International Conference on Controlled Fusion, Vol. 1, p. 595 (1974).

14. M. N. Bussac, D. Edery, K. Pellat, and J. L. Soule, Paper B3 in Proc. Sixth International Conference on Plasma Physics and Controlled Nuclear Fusion Research (1976).

15. Bruno Coppi, Massachusetts Institute of Technology (1976), private communication.

16. D. J. Sigmar, J. F. Clarke, R. V. Neidigh, and K. L. Vander Sluis, Phys. Rev. Lett. $\underline{33}, 1376$ (1974).

17. M. N. Bussac, R. Pellat, D. Edery, and J. L. Şoule, Phys. Rev. Lett. 35, $1638(1975)$.

18. Young-ping Pao, Phys. Fluids 19, 1796 (1976). 


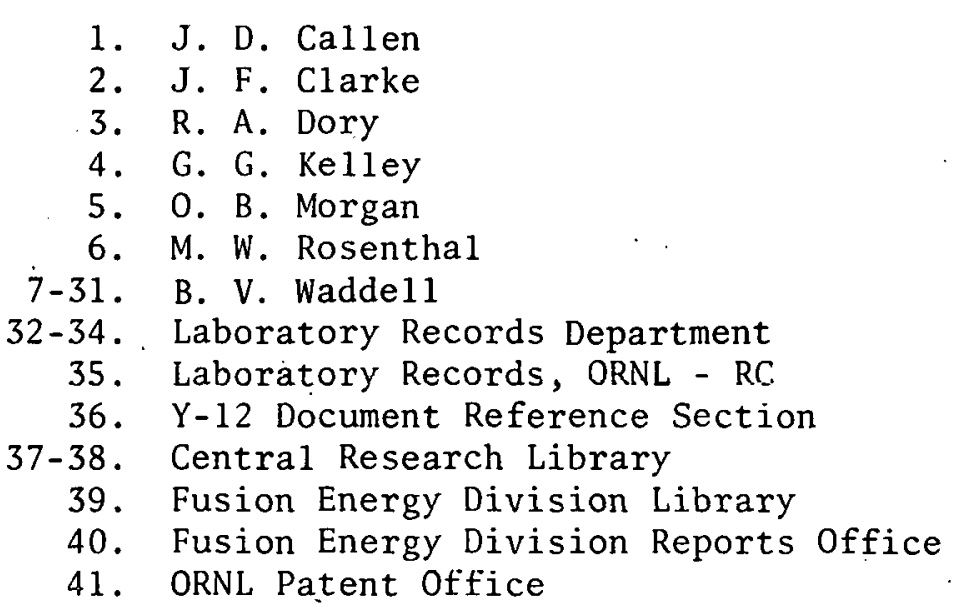

EXTERNAL DISTRIBUTION

42. Plasma Physics Library, Plasma Physics Laboratory, Princeton Univ., Forrestal Campus, P.0. Box 451, Princeton, NJ 08540

43. Controlled Thermonuclear Research Library, Lawrence Livermore Laboratory, P.0. Box 808, Livermore, CA 94550

44. Q Division Library, c/o F. L. Ribe, Los Alamos Scientific Laboratory, P.O. Box 1663, Los Alamos, NM 97544

45. Controlled Thermonuclear Researcn Library, c/o Weston M. Stacey, Jr., Argonne National Laboratory, 9700 S. Cass Ave., Argonne, IL 60439

46. CTR Computer Center, c/o Dr. John Killeen, Lawrence Livermore Laboratory, P.0. Box 808, Livermore, CA 94550

47. Librarian, Culham Laboratory, U.K. Atomic Energy Authority, Abingdon, Oxon, OX14 3DB, United Kingdom

48. Ruth Lengye, Bibliothek, Max-Planck Institut für Plasmaphysik, 8046 Garching bei München, Federal Repub1ic of Germany

49. Library, Centre de Recherches en Physique des Plasmas, 21 Avenue des Bains, 1007, Lausanne, Switzerland

50. A. M. Dupas, Documentation S:I.G.N., Départment de la Physique du Plasma et de la Fusion Controlée, Association EURATOM-CEA sur la Fusion, Centre d'Etudes Nucléaires, BP 85 Centre Du TRI 38041 Grenoble Cedex (France)

51. Bibliothèque, Service du Confinement des Plasmas, C.E.A., B.P. No. 6, 92, Fontenay-aux-Roses (Seine) France

52. Library, International Centre for Theoretical Physics, Trieste, Italy

53. Library, Laboratorio Gas Ionizzati, Frascati, Italy

54. V. E. Ivanov, Physical-Technical Institute of the Ukranian Academy of Sciences, Sukhumi, U.S.S.R.

55. L. M. Kovrizhnikh, Lebedev Institute of Physics, Academy of Sciences of the U.S.S.R., Leninsky Prospect 53, Moscow, U.S.S.R.

56. L. M. Kovrizhnikh, Lebedev Institute of Physics, Academy of Sciences of the U.S.S.R., Leninsky Prospect 53, Moscow, U.S.S.R.

57. Library, Inst. for Plasma Physics, Nagoya Univ., Nagoya, Japan 464 
58. Library, FOM-Institut voor Plasma-Fysica, Rijnhuizen, Jutphaas, Netherlands

59. Plasma Physics Group, Department of Engineering Physics, Australian National University, P.0. Box 4, Canberra A.C.T. 2600, Australia

60. Thermonuclear Library, Japan Atomic Energy Research Institute, Tokai, Naka, Ibaraki, Japan

61. Dr. D. G. McAlees, Exxon Nuclear Co., Inc., Research \& Technology Laser Enrichment Department, 2955 George Washington Way, Richland, WA 99352

62. CTR Reading Room, c/o Prof. D. W. Kerst, Dept. of Physics, Sterling Hal1, Univ. of Wisconsin, Madison, WI 53706

63. CTR Reading Room, c/o Prof. I. B. Bernstein, Yale Univ., 200 Mason Laboratory, Dept. of Engineering of Applied Science, New Haven.

CT 06510

64. Center for Plasma Physics and Thermonuclear Research, c/o D. W. Ross, Physics Dept., Univ. of Texas, Austin, TX 78712

65. CTR Reading Room, c/o Prof. B. D. Fried, Physics Dept., Univ, of Californià, I,ns Angeles, Cᄉ 00024

66. CTR Reading Room, c/o Prof. David C. Montgnmery, Physics \& Astron= omy Dept., Univ. of Iowa, Iowa City, IA 52240

67. Magneto-Fluid-nynamics Library, $c / 0 \mathrm{D}_{1}$. Haruld Grad, lourant Inst. of Math. Sci., New York Univ., 251 Mercer St., New York, NY 10012

68. CTR Reading Room, c/o Prnf. Allan N. Kaufman, Physics Dept., Univ. of California, Berkeley, CA 94720

69. Dr. David A. Dingee, Fusion Programs, Battelle-Northwest, Battelle Boulevard, Richland, WA 99352

70. CTR Reading Room, c/o Prof. C. S. Liu, Dept. of Physics and Astronomy, Univ. of Maryland, Collcgc Park, MD 20742

71. CTR Reading Room, c/o Prof. T. Kammash, 103 Research Admin. B1dg., N. Campus, Univ. of Michigan, Ann Arbor, MI 48105

72. CTR Reading Room, c/u Dr. Rav1 N. Sudan, Phillips Ha11, Cornel1 Univ., Ithaca, NY 14850

73. Prof. Marshali N. Kosenbluth, İnstitute for Advanced Study, Princeton, $\mathrm{NJ} 08540$

74. CTR Reading Room, c/o Prof. R. Gross, Plasma Research Lab., Columbia Univ., New York, NY 10027

75. C'TR Reading Room, c/o Prof. Roy Gould, California Inst. of Tech., M.S. 116-81, Pasadena, CA 91125

76. Dr. Nicholas A. Kra11, Science Applications, Inc., P.0. Box 2354, 1200 Prospect St., La Jolla, CA 92037

77. CTR Reading Room, c/o Dr. Jay P. Boris, Plasma Physics, Naval Research Laboratory, Washington, DC 20390

78. Profcasor A. Sillun, Dcpt. of Mechanical \& Aerospace Scienres, Universily of Rochester, Rochester, NY 14627

79. CTR Library, c/o Dr. Alan F. Haught, United Technologies Research Labs, East Hartford, CT 06108

80. Dr. H. K. Forsen, Exxon Nuclear Co., Inc. 777-106th Avenue, NE, C-000777, Bellevue, WA y8009

81. Dr. George Vahala, Physics Dept., College of William \& Mary, Williamsburg, VA 23185

82. Dr. Robert E. Price, Division of Magnetic Fusion Energy, G-234, Energy Research and Development Administration, Washington, D.C. 20545 
83. Dr. R. C. Davidson, Division of Magnetic Fusion Energy, G-234, Energy Research and Development Administration, Washington, D.C. 20545

84. Dr. Oscar P. Manley, Division of Magnetic Fusion Energy, G-234, Energy Research and Development Administration, Washington, D.C. 20545

85. Mr. E. E. Kintner, Division of Magnetic Fusion Energy, G-234, Energy Research and Development Administration, Washington, D.C. 20545

86. Dr. L. D. Pearlstein, L-388, Lawrence Livermore Laboratory, P.0. Box 808 , Livermore, CA 94550

87. Dr. J. P. Friedberg, Los Alamos Scientific Laboratory, Los Alamos, NM 87544

88. Dr. David J. Rose, Dept. of Nuclear Engineering, MIT, Cambridge, MA 02139

89. Dr. Gareth E. Guest, General Atomic Co., P.O. Box 81608, San Diego, CA 92138

90. Dr. Claude Mercier, Service du Theorie des Plasmas, Centre d'Etudes Nucléaires, Fontenay-aux-Roses (Seine) France

91. Dr. J. B. Taylor, Culham Laboratory, UKAEA, Abingdon, Oxon, OX14 3DB, United Kingdom

92. Dr. D. Pfirsch, Institute for Plasma Physics, 8046 Garching bei München, Federal Republic of Germany

93. Dr. V. D. Shafranov, I. V. Kurchatov Inst. of Atomic Energy, 46 Ulitsa Kurchatova, P.0. Box 3402, Moscow, U.S.S.R.

94. Dr. A. Rogister, Institute for Plasma Physics, KFA, Postfach 1913, D-5170, Jülich 1, Federal Republic of Germany

95. Dr. J. G. Cordey, Culham Laboratory, UKAEA, Abingdon, Oxon, OX14 3DB, United Kingdom

96. Dr. David Baldwin, L-388, Lawrence Livermore Lab., P.O. Box 808, Livermore, CA 94550

97. CTR Reading Room, c/o Prof. Bruno Coppi, Dept. of Physics, MIT, Cambridge, MA 02138

98. Dr. Harold P. Furth, Princeton Plasma Physics Lab., Princeton Univ., P.0. Box 451, Princeton, NJ 08540

99. Dr, Paill H. Rutherford, Princeton Plasma Physics Lab., Princeton Univ., P.0. Box 451, Princeton, NJ 08540

100. Dr. Herbert H. Woodson, Dept. of Electrical Engineering, Univ. of Texas, Austin, TX 78712

101. Research \& Technical Support Div., Oak Ridge Operations, Energy Research and Development Administration, P.O. Box E, Oak Ridge, TN 37830

102-128. Technical Information Center, Energy Research and Development Administration, P. 0. Box 62, Oak Ridge, TN 37830 